\title{
Shared Genetic Effects among Measures of Cognitive Function and Leukoaraiosis
}

\author{
Jennifer A. Smith1, Thomas H. Mosley, Jr.2, \\ Stephen T. Turner ${ }^{3}$ and Sharon L. R. Kardia ${ }^{1}$ \\ ${ }^{1}$ Department of Epidemiology, University of Michigan, Ann Arbor, MI \\ ${ }^{2}$ Department of Medicine, University of Mississippi Medical Center, Jackson, MS \\ ${ }^{3}$ Department of Internal Medicine, Mayo Clinic, Rochester, MN
}

USA

\section{Introduction}

The aging process influences cognitive and physical functioning through a variety of biological mechanisms. Multiple facets of cognitive function decline with age, including executive function, memory, language, visuomotor coordination, and information processing speed. Strong epidemiological trends show that areas of brain injury due to ischemic damage also increase with age. Areas of ischemic damage known as leukoaraiosis appear as hyperintense spots on MRI of the white matter of the brain. Leukoaraiosis is a strong predictor of ischemic stroke and vascular dementia, independent of other known risk factors (Markus et al., 2005). It is also strongly associated with cognitive impairment and cognitive decline in individuals who have not yet progressed to dementia (Pantoni et al., 2007; Schmidt et al., 2007).

Few studies have examined the genetic contribution to later-age cognitive changes in relationship to markers of subclinical ischemic brain injury such as leukoaraiosis. After increasing age, the main risk factors for leukoaraiosis are elevated blood pressure and lack of hypertension control (van Dijk et al., 2004). However, there is a significant amount of inter-individual variation in leukoaraiosis among subjects with similar duration and severity of hypertension (Schmidt et al., 2004; Szolnoki \& Melegh, 2006). Cognitive functioning is also highly variable, and it is likely that genetic variability accounts for a significant portion of the variation in both structural characteristics of the brain such as leukoaraiosis and measures of cognitive function (Deary et al., 2004).

In this chapter, we present a review of the biological mechanisms that influence leukoaraiosis and cognitive function, discuss the public health implications of the clinical manifestations of cerebrovascular disease, and explore the broad genetic attributes that explain inter-individual variation and covaraition (i.e., pleiotropy) among these brain traits.

\subsection{Biological mechanisms that influence leukoaraiosis and cognitive function} 1.1.1 Physiology and pathology of cerebrovascular disease and leukoaraiosis

The human brain is composed of gray matter (the cerebral cortex) that is responsible for consciousness, movement, and cognition and white matter that consists of nerve fibers that 
transmit impulses among cerebral areas and to the central nervous system. Leukoaraiosis is visible as bright spots in the white matter on T2-weighted MRIs (Markus, 2008; O'Sullivan, 2008). Leukoaraiosis ranges in severity from small, distinct areas of white matter hyperintensity (punctuate lesions) to large regions of white matter hyperintensity (early confluent or confluent lesions) (O'Sullivan, 2008). Leukoaraiosis is thought to be a marker of cerebral small vessel disease (cerebrovascular disease) in the long, narrow penetrating arterioles that supply the white matter with blood (Markus, 2008). This type of small vessel disease is defined by areas of diffuse arteriolosclerosis with deposits of a proteinaceous substance that includes fibrin, amyloid, and collagen, which results in thickening of the vessel and chronic ischemia that leads to demyelination, axonal loss, and gliosis (Markus, 2008; O'Sullivan, 2008). It occurs in regions of the brain that have low perfusion pressure, such as the deep white matter, and results in chronic ischemia and multiple diffuse infarctions due to small vessel occlusions (lacunar infarctions), both of which are visible as hyperintensity on MRIs (Markus, 2008). In regions of leukoaraiosis, there appears to be decreased blood flow (hypoperfusion) and impaired ability to regulate blood flow (autoregulation) (Markus, 2008).

Recently, it has been suggested that endothelial dysfunction, characterized by the inability of endothelial cells to perform tasks such as mediation of coagulation, platelet adhesion, and immune response, may be the intermediate process between hypertension and the alterations in blood flow observed in areas of leukoaraiosis (Hassan et al., 2003; Markus, 2008). Circulating endothelial markers may show a pro-coagulant pattern of endothelial function (e.g. higher circulating levels of thrombomodulin (TM) and lower circulating levels of tissue factor pathway inhibitor (TFPI)) that is specific to leukoaraiosis (Hassan et al., 2003) and may be related to progression of leukoaraiosis (Markus et al., 2005). Further support for endothelial dysfunction comes from the strong association between leukoaraiosis and elevated homocysteine level, which is hypothesized to be a mediator of endothelial damage (Hassan et al., 2004).

\subsubsection{Hypertension as a predictor of leukoaraiosis}

Development of leukoaraiosis is thought to be a marker of one of the major mechanistic pathways between hypertension and clinical endpoints such as ischemic stroke and vascular dementia, and is a known risk factor for both of these endpoints (Markus et al., 2005; O'Sullivan, 2008). Inadequately controlled hypertension gives rise to ischemic damage of the brain that is thought to be the manifestation of underlying cerebrovascular disease (Turner \& Boerwinkle, 2000). Several studies have also demonstrated an association between hypertension in midlife and cognitive decline in later life (Launer et al., 2000), and it has been hypothesized that this is due to the cumulative effects of subclinical damage due to small vessel disease (Knopman et al., 2001) with leukoaraiosis as a detectable sign of one of the main mechanistic pathways implicated (Sierra \& Coca, 2006). Hypertension is a leading risk factor for ischemic stroke (Roger et al., 2011) and for cognitive decline leading to vascular dementia (Launer et al., 2000). Hypertension affects approximately 1 in 3 American adults (76.4 million people), and accounts for $\$ 43.5$ billion in yearly direct and indirect costs in the United States (Roger et al., 2011).

\subsubsection{The relationship between leukoaraiosis and cognitive function}

In a review of studies pertaining to leukoaraiosis and cognition, Pantoni et al. (2007) conclude that despite different study characteristics, there is almost invariably evidence of 
an effect of leukoaraiosis on cognition. In particular, leukoaraiosis is more strongly associated with decreasing executive function than memory and is also associated with a decline in motor performance such as gait disturbances (Pantoni et al., 2007; Schmidt et al., 2007). The rate of progression of leukoaraiosis over time is also related to cognitive decline, and the severity of leukoaraiosis at baseline is a significant predictor of progression (Schmidt et al., 2007). It is also important to keep in mind, however, that other factors may affect the association between leukoaraiosis and cognitive decline such as brain atrophy and stroke (Pantoni et al., 2007; Schmidt et al., 2007).

\subsubsection{Cognitive decline and vascular dementia}

Dementia is a heterogeneous group of disorders with variable etiology that involves impairment in cognitive domains such as memory, executive function, and language as well as specific physical impairments such as gait abnormalities that cause significant impairment in social or occupational function and represent a decline from a previous level of functioning (American Psychiatric Association, 2000). The differential diagnosis of vascular dementia $(\mathrm{VaD})$, incorporates the underlying vascular cause as well as the cognitive and physical symptomology (Pohjasvaara et al., 2000), specifically "focal neurological signs and symptoms or laboratory evidence indicative of cerebrovascular disease (multiple infarctions involving cortex and underlying white matter) that are judged to be etiologically related to the disturbance" (American Psychiatric Association, 2000). Leukoaraiosis and multiple lacunar (small vessel) strokes, both caused by cerebrovascular disease, are the primary markers of VaD (Geldmacher \& Whitehouse, 1997) and are thought to be contributors to cognitive impairment in individuals who have not yet progressed to dementia (Pantoni et al., 2007; Schmidt et al., 2007). Several studies have also shown that leukoaraiosis is predictive of incident VaD (Prins et al., 2004).

\subsubsection{Complexity in the inter-relationships among clinical outcomes and sub-clinical measures}

A complex relationship exists among hypertension, leukoaraiosis, cognitive decline, dementia, and stroke. The figure below illustrates what is currently known about the interrelationships among these clinical outcomes and subclinical measures, including:

- Leukoaraiosis is thought to be a manifestation (sub-clinical marker) of cerebrovascular disease.

- Hypertension is a primary risk factor for leukoaraiosis.

- Leukoaraiosis is a risk factor for cognitive decline and ischemic stroke.

- Leukoaraiosis, ischemic stroke, and cognitive decline are included in the clinical criteria for the diagnosis of vascular dementia.

- Ischemic stroke (without additional evidence of leukoaraiosis) is a risk factor for cognitive decline.

\subsection{Public health implications of the clinical manifestations of cerebrovascular disease}

The clinical outcomes that are associated with cerebrovascular disease have large public health implications. Ischemic stroke accounts for $87 \%$ of all strokes, a leading cause of morbidity, mortality, and economic burden in the US (Roger et al., 2011). Stroke is the second most common cause of death and disability-adjusted life-years in industrialized 
countries (Lopez et al., 2001) and the third most common cause of death in the US, accounting for approximately 1 in 18 deaths in 2007 (Roger et al., 2011). Over 7 million Americans currently living with the cognitive and physical consequences of stroke (Roger et al., 2011), and it has been estimated that stroke account for approximately $4 \%$ of all direct health care costs in the US (Donnan et al., 2008). The risk of first-ever stroke is almost twice as high for African Americans as for white Americans, which may in part be due to the higher prevalence of hypertension in this group (Roger et al., 2011).

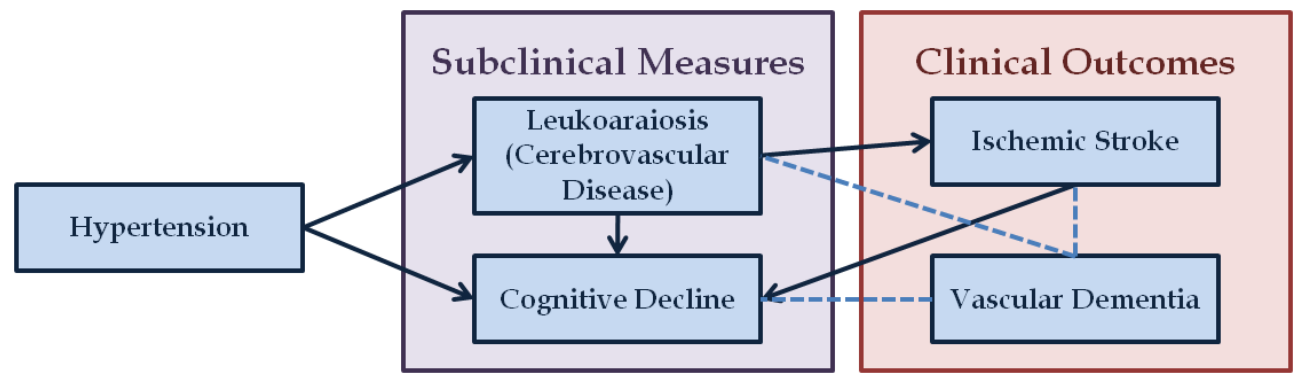

Fig. 1. Relationship between subclinical measures and clinical outcomes. Dark blue arrows represent risk factor relationships, and dashed blue lines represent clinical criteria.

Dementia is also an important public health burden in the U.S. and abroad (Haan \& Wallace, 2004), and the World Health Organization predicts that there will be approximately 29 million people affected by all forms of dementia by the year 2020 (Essink-Bot et al., 2002). Alzheimer's disease (AD) and other dementias affect over 5.2 million Americans, including between 200,000 and 500,000 people under the age of 65 . Dementias place a heavy economic burden on the health care system, with each Medicare patient with dementia accounting for more than three times as much spending than the average beneficiary (Alzheimer's Association, 2008). The aging population of the U.S. is expected to dramatically increase the prevalence of dementia, which is thought to affect $3 \%-11 \%$ of people older than 65 and $25 \%$ $47 \%$ of people older than 85 (Boustani et al., 2003). Older African Americans are about twice as likely to develop $\mathrm{AD}$ and other dementias as older white Americans, which may in part be due to the higher prevalences of hypertension and diabetes and lower average socioeconomic status of this group (Alzheimer's Association, 2010).

\subsection{Role of genetics in leukoaraiosis and cognitive function}

Genetic factors are likely to account for a significant amount of the inter-individual variation in cognitive functioning and brain structure (Deary et al., 2004). Heritability studies, candidate gene studies, and genome-wide association studies are beginning to shed light on the biological processes involved in the progression from hypertension to the development of leukoaraiosis and cognitive decline that are indicators of increased risk of stroke and dementia.

\subsubsection{Genetics of leukoaraiosis and cognitive function}

Estimates of heritability for leukoaraiosis range from $0.45-0.71$, indicating that genetic factors account for a large proportion of the inter-individual variation in this trait (Atwood et al., 2004; Carmelli et al., 1998; Turner et al., 2004). Candidate gene studies for 
leukoaraiosis have primarily concentrated on genes in pathways known to be involved in hypertension, vasculature, and endothelial damage. Although initial findings have been encouraging, no specific genetic factors have been unequivocally shown to be associated with this trait (Paternoster et al., 2009). Genome-wide association studies (GWAS) for this trait have also been limited, but are currently being conducted in several ethnic groups. To date, the most promising evidence for association is with a region on chromosome 17q25 in European Americans (Fornage et al., 2011).

For cognitive decline, the most promising candidate genes include those that are associated with hypertension, leukoaraiosis, Alzheimer's Disease (AD), normal cognitive functioning, cardiovascular function, oxidative stress, and inflammation (Deary et al., 2004), though candidate gene studies have not yet established any specific genetic factors that definitively affect cognitive decline. GWAS for a variety of cognitive traits are currently underway. GWASs that examine the change of cognitive traits over time in multiple cohorts will be particularly useful for identifying genetic factors associated with cognitive decline.

\subsubsection{Role of pleiotropy}

Pleiotropy is most simply defined as the condition in which variation in a single gene affects multiple traits (Hodgkin, 1998). Defined in this manner, pleiotropic genes range from those that encode proteins involved in a single biological pathway that influences multiple disease processes and/or organ systems to those that play entirely different roles in multiple biological pathways. In some instances, pleiotropy is "the phenomenon in which a single gene controls several distinct, seemingly unrelated, phenotypic effects" (Zou et al., 2008). A well-known example of pleiotropy in humans is the $\varepsilon 4$ allele of the apolioprotein $\mathrm{E}(A P O E)$ gene (Dickstein et al., 2010). APOE is a plasma cholesterol transport molecule that resides primarily on very low density lipoproteins, and the $\varepsilon 4$ allele has been shown to be a risk factor for coronary heart disease and stroke through mechanisms related directly to lipid transport. However, the $\varepsilon 4$ alelle is also a risk factor for $\mathrm{AD}$ and cognitive decline, with those carrying the allele having a younger age of onset as well as an accelerated pace of cognitive decline. Though the precise mechanism by which $\varepsilon 4$ leads to cognitive decline is not known, the main hypotheses are through pathways not directly related or only tangentially related to lipid transport. APOE appears to affect brain traits through its role as a chaperone for the amyloid beta protein and/or mediation of the phosphorylation of the tau protein.

The study of pleiotropy in model organisms and humans serves several functions. In model organisms, it serves to further the understanding and elucidation of the complex biological pathways that regulate the development of traits, providing information about normal cellular function, normal development and function at the organismal level, connections between previously unrecognized biological processes, and increased predictive ability in breeding programs (Hodgkin, 1998). It also it provides insight into the mechanisms of evolution, as effects on multiple traits due to a single genetic variant may pose severe evolutionary constraints (Cheverud et al., 2004). The findings from pleiotropy studies in model organisms, particularly the high degree of connectivity among transcriptional modules, have strong implications for understanding the pleiotropic genetic mechanisms that are also operating in humans. A greater understanding of the underlying pleiotropic mechanisms contributing to human health and disease has the potential to allow for earlier identification of individuals at increased risk for disease, the development of more efficacious treatments, and the tailoring of particular treatments to people most likely to respond positively. 


\subsubsection{Bivariate variance component analysis to assess pleiotropy}

Studies of pleiotropy in humans have generally consisted of bivariate genetic analysis using variance decomposition techniques and linkage analysis in biologically related groups of traits. Variance decomposition techniques are used to parse the total phenotypic correlation in a pair of traits into the correlation due to genetic influences (genetic correlation) and the correlation due to environmental influences (environmental correlation) using family relationships.

Bivariate variance decomposition techniques have been used to study pleiotropy in humans for a variety of purposes. Comuzzie et al. (1994) estimated the genetic and environmental correlations among eight measures of skinfolds in order to inform epidemiologic studies that examine these measures as risk factors for heart disease and diabetes. The authors argue that studying pleiotropy in risk factors is important because shared genetic or environmental effects may confound analyses using these traits if these effects are unrecognized. Bivariate genetic analysis is has also been used to identify measureable endophenotypes that can be used to study the genetic underpinnings of complex diseases with multiple etiologies. For example, Charlesworth et al. (2010) examined the genetic correlations between several quantitative characteristics of the eye and primary open-angle glaucoma in order to determine the most appropriate endophenotypes to focus on in genetic association studies.

\subsection{Motivation for studying pleiotropy of leukoaraiosis and cognitive function}

In this chapter, we focus on estimating the heritabilities, genetic correlations, and environmental correlations between leukoaraiosis and seven measures of neurocognitive function. In a sample of 759 whites and 720 African Americans, we examine patterns of pleiotropy using a bivariate variance components approach. Findings of this work help inform the understanding of the genetic relationships among leukoaraiosis and measures of cognitive function. A deeper understanding the genetics of leukoaraiosis development and its impact on cognitive decline in individuals free of overt neurocognitive disorders may help to inform pharmacogenomic drug development and preventive strategies for identifying individuals at increased risk of stroke and dementia. Research into the genetic architecture of leukoaraiosis and cognitive function in samples that are presymptomatic is particularly important because preventive interventions for dementia would need to start early, preferably before any brain damage occurs (DeKosky \& Marek, 2003).

\section{Methods}

\subsection{Sample}

The National Heart, Lung and Blood Institute established the Family Blood Pressure Program (FBPP) in 1996 from four existing research networks that were investigating the genetics of hypertension and its sequelae (FBPP Investigators, 2002), including The Genetic Epidemiology Network of Arteriopathy (GENOA). GENOA recruited hypertensive sibships from Rochester, Minnesota and Jackson, Mississippi for linkage and association studies to investigate the genetic underpinnings of hypertension and target organ damage related to hypertension (Daniels et al., 2004).

In the initial phase of the GENOA study (Phase I: 1996-2001), all members of sibships containing $\geq 2$ individuals with essential hypertension clinically diagnosed before age 60 were invited to participate, including both hypertensive and normotensive siblings $(1,583$ 
non-Hispanic whites and 1,841 African Americans). The diagnosis of essential hypertension was established based on blood pressure levels measured at the study visit $(>140 \mathrm{mmHg}$ average systolic BP or $>90 \mathrm{mmHg}$ average diastolic BP) or a prior diagnosis of hypertension and current treatment with antihypertensive medications. Exclusion criteria were secondary hypertension, alcoholism or drug abuse, pregnancy, insulin-dependent diabetes mellitus, or active malignancy. In the second phase of the GENOA study (Phase II: 2000-2004), 1,241 white and 1,482 African American participants were successfully re-recruited to measure potential target organ damage due to hypertension. Phase I and II GENOA data consist of demographic information, medical history, clinical characteristics, lifestyle factors, and blood samples for genotyping and biomarker assays. Written informed consent was obtained from all subjects and approval was granted by participating institutional review boards. All reported phenotype and covariate data used for this analysis was collected during the Phase II exam.

The Genetics of Microangiopathic Brain Injury (GMBI) study (2001-2006) is an ancillary study of GENOA undertaken to investigate susceptibility genes for ischemic brain injury. Phase II GENOA participants that had a sibling willing and eligible to participate in the GMBI study underwent a neurocognitive testing battery to assess several domains of cognitive function including learning, memory, attention, concentration, and language. Ischemic brain damage to the subcortical and periventricular white matter (leukoaraiosis) was quantified by magnetic resonance imaging (MRI) in subjects who had no history of stroke or neurological disease and no implanted metal devices. Participants were excluded from this analysis if they were less than 45 years of age or had evidence of silent stroke (transient ischemic attack) upon examination of their MRI. The analysis sample was comprised of 762 whites in 378 sibships and 720 African Americans in 413 sibships.

\subsection{Leukoaraiosis}

Leukoaraiosis volume $\left(\mathrm{cm}^{3}\right)$ was obtained via MRI in a separate clinical visit. All MRI scans were performed on identically equipped Signa 1.5 T MRI scanners (GE Medical Systems, Waukesha, WI, USA) and images were centrally processed at the Mayo Clinic. Symmetric head positioning with respect to orthogonal axes was verified by a series of short scout scans. Total intracranial volume (head size) was measured from T1-weighted spin echo sagittal images, each set consisting of 32 contiguous $5 \mathrm{~mm}$ thick slices with no interslice gap, field of view $=24 \mathrm{~cm}$, matrix $=256 \times 192$, obtained with the following sequence: scan time $=2.5 \mathrm{~min}$, echo time $=14 \mathrm{~ms}$, repetitions $=2$, replication time $=500 \mathrm{~ms}$ (Jack et al., 1989). Total brain and leukoaraiosis volumes were determined from axial fluid-attenuated inversion recovery (FLAIR) images, each set consisting of 48 contiguous 3-mm interleaved slices with no interslice gap, field of view $=22 \mathrm{~cm}$, matrix $=256 \times 160$, obtained with the following sequence: $\mathrm{scan}$ time $=9 \mathrm{~min}$, echo time $=144.8 \mathrm{~ms}$, inversion time $=2,600 \mathrm{~ms}$, repetition time $=26,002 \mathrm{~ms}$, bandwidth $=+/-15.6 \mathrm{kHz}$, one signal average. A FLAIR image is a T2-weighted image with the signal of the cerebrospinal fluid nulled, such that brain pathology appears as the brightest intracranial tissue. Interactive imaging processing steps were performed by a research associate who had no knowledge of the subjects' personal or medical histories or biological relationships. A fully automated algorithm was used to segment each slice of the edited multi-slice FLAIR sequence into voxels assigned to one of three categories: brain, cerebrospinal fluid, or leukoaraiosis. The mean absolute error of this method is $1.4 \%$ for brain volume and $6.6 \%$ for leukoaraiosis volume, and the mean test- 
retest coefficient of variation is $0.3 \%$ for brain volume and $1.4 \%$ for leukoaraiosis volume (Jack et al., 2001). White matter hyperintensities in the corona-radiata and periventricular zone, as well as central gray infarcts (ie, lacunes) were included in the global leukoaraiosis measurements. Brain scans with cortical infarctions were excluded from the analyses because of the distortion of the leukoaraiosis volume estimates that would be introduced in the automated segmentation algorithm.

\subsection{Neuropsychological testing battery}

Neuropsychological tests were conducted in a private room that was free of noise and other distractions by trained interviewers. In order to assure accuracy and comparability in test administrator performance, a portion (approximately 5\%) of all interviews were tape recorded and evaluated for accuracy to provide feedback to test administrators. The neuropsychological outcome measures used for this analysis are presented in Table 1 along with the cognitive functions assessed.

\begin{tabular}{|c|c|c|}
\hline Neurocognitive Test & $\begin{array}{l}\text { Outcome } \\
\text { Measure }\end{array}$ & Cognitive Functions \\
\hline $\begin{array}{l}\text { Rey's Auditory Verbal } \\
\text { Learning Test (RAVLT) }\end{array}$ & $\begin{array}{l}\text { RAVLT } \\
\text { delayed recall }\end{array}$ & $\begin{array}{l}\text { Learning } \\
\text { Delayed memory } \\
\text { Vulnerability to interference }\end{array}$ \\
\hline $\begin{array}{l}\text { Rey's Auditory Verbal } \\
\text { Learning Test (RAVLT) }\end{array}$ & $\begin{array}{l}\text { RAVLT total } \\
\text { learning }\end{array}$ & $\begin{array}{l}\text { Learning } \\
\text { Immediate memory }\end{array}$ \\
\hline $\begin{array}{l}\text { Digit Symbol Substitution } \\
\text { Test (DSST) }\end{array}$ & DSST & $\begin{array}{l}\text { Psychomotor speed } \\
\text { Visual attention } \\
\text { Concentration }\end{array}$ \\
\hline $\begin{array}{l}\text { Controlled Oral Word } \\
\text { Association Test (COWA) }\end{array}$ & COWA FAS & $\begin{array}{l}\text { Language } \\
\text { Verbal fluency (phonetic association) }\end{array}$ \\
\hline $\begin{array}{l}\text { Controlled Oral Word } \\
\text { Association Test (COWA) }\end{array}$ & $\begin{array}{l}\text { COWA } \\
\text { animals }\end{array}$ & $\begin{array}{l}\text { Language } \\
\text { Category fluency (semantic association) }\end{array}$ \\
\hline Stroop Color Word Test & $\begin{array}{l}\text { Stroop color } \\
\text { word }\end{array}$ & $\begin{array}{l}\text { Concentration effectiveness } \\
\text { Ability to shift perceptual sets in } \\
\text { response to novel stimuli }\end{array}$ \\
\hline Stroop Color Word Test & $\begin{array}{l}\text { Stroop } \\
\text { interference }\end{array}$ & $\begin{array}{l}\text { Ability to shift perceptual sets in } \\
\text { response to novel stimuli }\end{array}$ \\
\hline
\end{tabular}

Table 1. Measures of cognitive function

\subsubsection{Rey's Auditory Verbal Learning Test (RAVLT)}

Rey's Auditory Verbal Learning Test (RAVLT) is a brief test that assesses learning and memory through multiple learning trials and a 30-minute delayed recall (Rey, 1964). Specifically, the measure assesses immediate memory span, new learning, vulnerability to interference in learning, and recognition memory. RAVLT testing norms for individuals aged 55 and older were developed through Mayo's Older Americans Normative Studies (MOANS), and the testing procedure followed in GMBI was identical to that used in MOANS (Ivnik et al., 1992). 
The examiner begins by reading a list of 15 common words aloud, and participants are asked to recall as many of the words as possible in any order. The same procedure is repeated four more times using the same list of 15 words. The total number of words that the participant remembers correctly over the five trials is recorded and forms the basis of the RAVLT total learning outcome measure for this analysis, which assesses immediate memory. Delayed recall is assessed by asking the participant to again name as many words as he/she remembers after a 30-minute delay, forming the basis of the RAVLT delayed learning outcome measure for this analysis. During the 30-minute interim, an interference task is performed in which the interviewer reads another set of words aloud, and the participant is asked to recall them. Thus, the delayed learning outcome assesses both delayed memory as well as vulnerability to interference.

\subsubsection{Wechsler Adult Intelligence Scale Revised (WAIS-R) Digit Symbol Substitution Task (DSST)}

The Digit Symbol Substitution task (DSS) from the Wechsler Adult Intelligence Scale Revised (WAIS-R) (Wechsler, 1981) is a timed translation test designed to measure complex visual attention, sustained and focused concentration, response speed, and visuomotor coordination (Lezak, 1995). In this test, participants are given a key in which each number corresponds to a special symbol. The task consists of filling in empty boxes below a series of random numbers with the symbol corresponding to the appropriate number (translating the numbers to symbols). After a practice session to ensure that the participant understands the task, participants were given a 90 second time limit to complete as many items as possible. The DSST outcome measure for this analysis was the number of correct symbols completed in 90 seconds.

\subsubsection{Controlled Oral Word Association Test (COWA) of the Multilingual Aphasia Examination}

The Multilingual Aphasia Examination was developed to diagnose the presence of aphasic disorders (any type of acquired language impairment), and the Controlled Oral Word Association Test (COWA) is a subset of this examination designed to measure verbal fluency (Lezak, 1995). Two measures of verbal fluency were used as outcomes for the present study, one of letter fluency (Word Fluency Test (WFT)) and one of category fluency (Animal Naming). The Word Fluency Test of the COWA assesses letter fluency (phonetic association) by asking subjects to generate words orally that begin with a specific letter of the alphabet " $\mathrm{F}$ ", " $\mathrm{A}$ ", and "S") for a period of 60 seconds. These letters were chosen because they have been demonstrated to allow more vocabulary choices overall than other letters. Scoring of this test consisted of adding the total number of admissible words generated for each of the three letters. Inadmissable words include proper nouns as well as variations, plurals, and repetitions of previously stated words.

The Animal Naming portion of the COWA assesses category fluency (semantic association) by asking subjects to name as many animals as possible in a period of 60 seconds (Lezak, 1995). Scoring of this test is the sum of all admissible animals. Inadmissable animals include extinct, imaginary, or magical animals, proper names, and variations of previously stated animals.

\subsubsection{Stroop Color Word (CW) Test}

The Stroop Color Word (CW) Test is primarily a measure of concentration effectiveness, specifically the ability to shift perceptual sets to correspond with changing demands and the 
ability to inhibit a customary response to stimulus in favor of a more novel one (Lezak, 1995; Stroop, 1935). Administration and scoring of the test to GMBI participants followed procedures outlined in the standardized version of the $\mathrm{CW}$ test developed by Golden (Golden, 1978).

This test consists of three pages: the word page, the color page, and the color-word page. The word page consists of the words "RED", "GREEN", and "BLUE" arranged randomly and printed in black ink. The color page consists of sets of " $X X X X$ " printed in red, green, or blue ink. The color-word page consists of the words from the word page printed in the colors on the color page, but no word matches the color in which it is printed (for example, the word "RED" is printed in either green or blue ink). For this study, the participant was first asked to read the word page as fast as he/she could for 45 seconds, and the total number of correct words was recorded. If the participant stated an incorrect word, the interviewer said, "No," and the participant was instructed to read the same word again to correct their error. The same procedure was followed for naming the colors on the color page. The participant was then asked to state the colors of the words on the color-word page as fast as he/she could in 45 seconds, and the total number of correctly stated colors were recorded.

Two measures from this test are used as outcomes in the present study. The color-word (CW) score is the total number of correctly stated colors out of 100 from the color-word page. The Stroop interference score is the difference in scores between the color page and the color-word page.

\subsection{Statistical analysis}

\subsubsection{Descriptive statistics}

Data management and statistical analyses were conducted primarily in $R$ version 2.8.0 ( $R$ Core Development Team, 2008). Distributional plots indicated that the measures of leukoaraiosis volume are severely right-skewed, so this variable was transformed by taking the natural log of (leukoaraiosis +1 ). The cognitive traits appeared to have relatively normal distributions; thus, no variable transformations were applied to these variables. T-tests were conducted for the outcome measures to test whether there were significant differences in the white and African American study participants.

\subsubsection{Covariates}

Biometrical modeling of leukoaraiosis and cognitive function included age at cognitive testing, gender, and education as covariates. Relative performance on cognitive tests is determined using age- and gender-specific population-based norms, since both of these variables are known to affect cognitive function. Age is also a very strong independent predictor for leukoaraiosis. Education affects performance on some cognitive tests, as people with higher educational attainment tend to perform better (Valenzuela \& Sachdev, 2006). For this analysis, education was categorized as follows: 0) less than high school, 1) completed high school (GED), 2) some college, and 3) completed college (4+ years). To account for differences in brain size, intracranial volume was also included in models of leukoaraiosis. We conducted multivariable linear mixed models with covariates as predictor variables for each outcome measure to explore the relationships between these variables and each outcome of interest in GENOA whites and African Americans.

\subsubsection{Biometrical genetic modeling}

The expected covariance of a trait between a pair of individuals can be modeled as a function of the variance parameters and the expected correlation between the individuals 
for genetic effects, based on family relationships (Sing et al., 1987). In this study, SOLAR (Sequential Oligogenic Linkage Analysis Routines) (Almasy \& Blangero, 1998) was used to implement a variance component regression based on maximum likelihood estimation to estimate the proportion of phenotypic variance that is due to additive genetic effects, giving an estimate of heritability. Shared residual (non-genetic) effects are assumed to be zero because the siblings in this study are all adults and have reported living in separate households.

Heritabilities were estimated for the outcome variables (all cognitive traits and $\ln ($ leukoaraiosis+1)) both with and without covariates (age, sex, education, and TIV) included in the biometric models. When covariates are included in the model, the heritability estimate is given by [(1-proportion of variance explained by covariates) $\left.{ }^{*} \mathrm{~h}^{2}\right]^{*} 100$, and represents the hertiability the residual variance of the trait that is not accounted for by the covariates.

The heritability of the traits were tested for significance by comparing the log-likelihood of the model in which heritability is estimated to that of the model in which heritability is fixed to 0 . The null distribution of the likelihood ratio test statistic is a 50:50 mixture of a Chisquare distribution with one degree of freedom and a point mass at zero.

\subsubsection{Phenotypic, genetic, and environmental correlations}

The phenotypic, genetic, and environmental correlations among all pairs of traits in both ethnic groups were estimated in SOLAR, both with and without covariates included in the biometric models. The estimated genetic and environmental correlations, $\rho_{g}$ and $\rho_{e}$, were tested for significance by comparing the log-likelihood of the model in which the parameter of interest is estimated to that of the model in which the parameter is fixed to 0 .

The test for pleiotropy, or evidence of shared genetic influences, is as follows: $\mathbf{H}_{\mathbf{0}}: \rho_{g}=0 \mathrm{vs}$. $\mathbf{H}_{\mathbf{a}}: \rho_{g} \neq 0$. The null distribution of the likelihood ratio test statistic statistic is a Chi-square distribution with one degree of freedom. Rejection of the null hypothesis provides evidence of pleiotropy.

The presence of shared environmental influences (non-genetic influences beyond the covariates included in the model) is tested similarly: $\mathbf{H}_{\mathbf{o}}: \rho_{e}=0 \mathrm{vs} . \mathbf{H}_{\mathbf{a}}: \rho_{e} \neq 0$. The null distribution of the likelihood ratio test statistic statistic is a Chi-square distribution with one degree of freedom. Rejection of the null hypothesis provides evidence that there are shared environmental influences on the traits.

\section{Results}

\subsection{Descriptive statistics}

Descriptive statistics of the outcome measures and covariates for the 762 white and 720 African American participants, as well as T-tests comparing the samples, are presented in Tables 2 and 3. GENOA whites are $58.1 \%$ female, have a mean age at the time of cognitive testing of 61.3 years (range $=45-84$ years), and have a mean leukoaraiosis volume of $8.11 \mathrm{~cm}^{3}$ (range $\left.=1.2-62 \mathrm{~cm}^{3}\right)$. GENOA African Americans have a much larger percentage of females $(72.6 \%)$, have a higher mean age of cognitive testing (63.3 years, range $=45-91$ years)), and have a higher mean volume of leukoaraiosis with greater variability $\left(9.56 \mathrm{~cm}^{3}\right.$, range $=2.0-126$ $\left.\mathrm{cm}^{3}\right)$. Approximately half of both whites and African Americans attended at least some college; however, only $5.2 \%$ of white participants did not graduate from high school or obtain a GED while this was true for $28.3 \%$ of African American participants. The mean 
values for all outcome measures were significantly different in whites and African Americans except for Stroop interference. Leukoaraiosis was strongly right skewed in both populations, but had a relatively normal distribution after taking the natural logarithm.

\begin{tabular}{|c|c|c|c|c|c|}
\hline \multirow[b]{2}{*}{ Trait } & \multirow[b]{2}{*}{ Category } & \multicolumn{2}{|c|}{ Whites } & \multicolumn{2}{|c|}{ African Americans } \\
\hline & & $\mathbf{N}$ & Percentage & $\mathbf{N}$ & Percentage \\
\hline \multirow[t]{4}{*}{ Education } & 0 (Less than HS) & 40 & $5.2 \%$ & 204 & $28.3 \%$ \\
\hline & 1 (HS/GED) & 329 & $43.2 \%$ & 205 & $28.5 \%$ \\
\hline & 2 (Some College) & 246 & $32.3 \%$ & 127 & $17.6 \%$ \\
\hline & 3 (Grad/Professional) & 147 & $19.3 \%$ & 184 & $25.6 \%$ \\
\hline \multirow[t]{2}{*}{ Gender } & Male & 319 & $41.9 \%$ & 197 & $27.4 \%$ \\
\hline & Female & 443 & $58.1 \%$ & 523 & $72.6 \%$ \\
\hline
\end{tabular}

Table 2. Descriptive characteristics of the samples

\begin{tabular}{|c|c|c|c|c|c|}
\hline Trait & $\mathbf{N}$ & Mean $( \pm S D)$ & $\begin{array}{c}\text { Afric } \\
\mathbf{N}\end{array}$ & $\begin{array}{c}\text { Americans } \\
\text { Mean } \\
( \pm S D)\end{array}$ & $\begin{array}{c}\text { T-test } \\
\text { P-valuea }\end{array}$ \\
\hline Leukoaraiosis volume, $\mathrm{cm}^{3}$ & 714 & $8.11(6.83)$ & 574 & $9.56(9.89)$ & 0.0028 \\
\hline Ln (leukoaraiosis+1) & 714 & $2.06(0.05)$ & 574 & $2.16(0.55)$ & 0.0002 \\
\hline RAVLT delayed recall & 758 & $9.08(3.27)$ & 708 & $6.80(3.36)$ & $<2.2 \mathrm{E}-16$ \\
\hline RAVLT total learning & 759 & $47.7(9.8)$ & 712 & $40.1(9.4)$ & $<2.2 \mathrm{E}-16$ \\
\hline DSST & 758 & $50.2(12.4)$ & 697 & $32.9(13.6)$ & $<2.2 \mathrm{E}-16$ \\
\hline COWA FAS & 760 & $32.4(13.6)$ & 687 & $28.6(11.7)$ & $1.96 \mathrm{E}-08$ \\
\hline COWA animals & 762 & $19.3(4.9)$ & 716 & $14.9(4.5)$ & $<2.2 \mathrm{E}-16$ \\
\hline Stroop color word & 740 & $34.5(9.3)$ & 648 & $22.3(10.1)$ & $<2.2 \mathrm{E}-16$ \\
\hline Stroop interference & 740 & $32.8(9.3)$ & 648 & $33.6(11.8)$ & 0.4450 \\
\hline
\end{tabular}

a T-test p-value for a test of equality of trait means in whites and African Americans.

Table 3. Comparison of outcome measures

\subsection{Associations between covariates and outcome measures}

In order to explore the relationship between covariates and each outcome of interest, we conducted multivariable linear mixed models with covariates as predictor variables for each outcome measure. In both whites and African Americans, age, gender, and education were significant predictors for all cognitive measures except that education was not a significant predictor of Stroop interference in whites and gender was not a significant predictor of Stroop color word in African Americans after accounting for the other covariates. As expected, increasing age was associated with lower cognitive scores, while increasing education was associated with higher cognitive scores. Female gender also showed a trend of being associated with higher cognitive scores. In both groups, increasing age and total intracranial volume were associated with increasing leukoaraiosis volume, while gender and education were not associated with this measure.

The amount of variance explained by the covariates, as measured by $\mathrm{R}^{2}$, showed a consistent pattern between the two groups. $\mathrm{R}^{2}$ was lowest for Stroop interference (0.018 in whites and 
0.074 in African Americans) and highest for DSST (0.411 in whites and 0.529 in African Americans). The amount of variance explained by covariates in the remainder of the cognitive measures ranged from 0.122 to 0.309 in whites and from 0.207 to 0.294 in African Americans. Variance of $\ln ($ leukoaraiosis +1$)$ explained by covariates was higher in whites (0.309) than in African Americans (0.213).

\subsection{Genetic variance (heritability)}

In order to examine the contribution of genetic factors to the observed variation in the traits, we used a biometrical approach to estimate the proportion of variance in the traits explained by genetic factors (heritabilities) both with and without inclusion of covariates in the models (Table 4). Heritabilities of all traits were highly significant in both whites and African Americans ( $p$-value<0.001) with the exception of Stroop interference in African Americans that showed only a marginally significant heritability, illustrating that all of the traits under study are influenced by genetic factors. Similar patterns of heritability were observed between the two groups, though African Americans tended to have lower heritabilities than whites for most traits.

\begin{tabular}{|c|c|c|c|c|}
\hline Trait & $\begin{array}{c}\mathbf{h}^{2} \text { for Trait } \\
\text { Modeled } \\
\text { without } \\
\text { Covariates }\end{array}$ & $\begin{array}{c}\mathbf{h}^{2} \text { for Trait } \\
\text { Modeled } \\
\text { with } \\
\text { Covariates }\end{array}$ & $\begin{array}{c}\text { Proportion } \\
\text { of Variance } \\
\text { Explained } \\
\text { by } \\
\text { Covariates }\end{array}$ & $\begin{array}{l}\text { Percent Variation } \\
\text { Due to Genetic } \\
\text { Factors After } \\
\text { Accounting for } \\
\text { Covariates }^{a}\end{array}$ \\
\hline \multicolumn{5}{|l|}{ Whites } \\
\hline Ln(leukoaraiosis+1) & $0.656^{* * *}$ & $0.529^{* * *}$ & 0.311 & 36.45 \\
\hline RAVLT delayed recall & $0.602^{* \star *}$ & $0.526^{* * *}$ & 0.222 & 40.92 \\
\hline RAVLT total learning & $0.627^{* \star *}$ & $0.516^{* * *}$ & 0.308 & 35.71 \\
\hline DSST & $0.774^{\star \star *}$ & $0.843^{* * *}$ & 0.403 & 50.33 \\
\hline COWA FAS & $0.441^{* * *}$ & $0.366^{* * *}$ & 0.139 & 31.51 \\
\hline COWA animals & $0.503^{* * *}$ & $0.349^{* * *}$ & 0.152 & 29.60 \\
\hline Stroop color word & $0.586^{* * *}$ & $0.429^{* * *}$ & 0.276 & 31.06 \\
\hline Stroop interference & $0.302^{* * *}$ & $0.275^{* * *}$ & 0.023 & 26.87 \\
\hline \multicolumn{5}{|l|}{ African Americans } \\
\hline Ln(leukoaraiosis+1) & $0.485^{* * *}$ & $0.432^{* * *}$ & 0.217 & 33.83 \\
\hline RAVLT delayed recall & $0.494^{* * *}$ & $0.390^{* * *}$ & 0.203 & 31.08 \\
\hline RAVLT total learning & $0.560^{\star \star *}$ & $0.440^{* * *}$ & 0.279 & 31.72 \\
\hline DSST & $0.810^{* \star *}$ & $0.556^{* * *}$ & 0.525 & 26.41 \\
\hline COWA FAS & $0.710^{\star \star *}$ & $0.536^{* * *}$ & 0.300 & 37.52 \\
\hline COWA animals & $0.551^{\star \star *}$ & $0.329^{* \star *}$ & 0.260 & 24.35 \\
\hline Stroop color word & $0.532^{* * *}$ & $0.440^{* \star *}$ & 0.232 & 33.79 \\
\hline Stroop interference & $0.135^{\star * *}$ & $0.154^{*}$ & 0.075 & 14.25 \\
\hline
\end{tabular}

a $\left[(1 \text { - Proportion of variance explained by adjustment covariates })^{*} \mathrm{~h}^{2}\right]^{*} 100$

For all traits modeled with covariates, biometric models included age, sex, and education. The biometric model for $\ln ($ leukoaraiosis +1 ) also included TIV.

Null hypothesis of tests: $\mathrm{h}^{2}=0$

${ }^{*} 0.01<$ p-value $<0.05,{ }^{* *} 0.001<$ p-value $<0.01,{ }^{* * *}$ p-value $<0.001$

Table 4. Trait heritabilities 
Heritabilities in traits modeled without covariates were lowest for Stroop interference $(0.302$ in whites, 0.135 in African Americans) and highest for DSST (0.774 in whites, 0.81 in African Americans), with the majority of heritabilities in the range of 0.45 to 0.6 . Leukoaraiosis had a higher heritability in whites (0.656) than in African Americans (0.485). After including covariates in the biometric models, heritabilities for the traits were generally lower but remained highly significant. Again, Stroop interference had the lowest heritability in both groups (0.275 in whites, 0.154 in African Americans) and DSST had the highest (0.843 in whites, 0.556 in African Americans), with the remaining traits ranging between 0.33 and 0.54. Leukoaraiosis still showed higher heritability in whites (0.529) than in African Americans (0.432).

The proportion of the observed trait variance accounted for by covariates estimated with biometric modeling mirrored the relationships we observed in multivariate linear mixed modeling, described above. The lowest proportion of variance explained was for Stroop interference (0.023 in whites, 0.075 in African Americans) and the highest was for DSST (0.403 in whites, 0.525 in African Americans). For the remainder of the traits, the proportion of variance explained by covariates ranged from 0.139 (COWA FAS) to 0.311 (leukoaraiosis) in whites and from 0.203 (RAVLT delayed recall) to 0.3 (COWA FAS) in African Americans. In order to determine the proportion of variation in the traits explained by genetic factors, we multiplied the proportion of variation not explained by the covariates by the heritability. Expressed as a percentage of total variation, genetic factors explain the lowest amount of variation in Stroop interference in both groups $(26.87 \%$ in whites, $14.25 \%$ in African Americans). The largest amount of variation explained by genetic factors in whites was for DSST $(50.33 \%)$ followed by RAVLT delayed recall (40.92\%) and leukoaraiosis $(36.45 \%)$. In African Americans, genetic factors explained the largest percentage of variation in COWA FAS (37.52\%) followed by leukoaraiosis (33.83\%) and Stroop color word $(33.79 \%)$. For the majority of traits, the amount of variation explained by genetic factors was lower in African Americans than in whites, but most traits in both groups had at least $25 \%$ of variation explained by genetic factors, showing that genetics has an important influence on these traits.

\subsection{Phenotypic correlations between trait pairs}

The patterns observed in the correlations estimated biometrically in SOLAR are presented in Table 5. The strongest correlation in the traits modeled with covariates was between the two RAVLT measures (0.755 in whites, 0.729 in African Americans), and the weakest correlations were between leukoaraiosis and all cognitive traits (ranging from -0.001 to -0.083 ). In general, multiple measures from the same test exhibited stronger correlations than measures across tests, which is intuitive since measures from the same test are assessing different but closely related cognitive functions. Patterns of correlation in whites and African Americans were very similar, though whites generally tended to exhibit somewhat stronger correlations.

\subsection{Genetic and environmental correlations between trait pairs}

In order to begin to understand the extent to which pleiotropic genetic effects may be contributing to each pair of traits, we used a biometrical approach to estimate genetic and environmental correlations (Table 6). Overall, there were far more significant genetic correlations (pleiotropic effects) between trait pairs than environmental correlations, indicating that shared genetic effects were more common in these pairs of traits than shared 


\begin{tabular}{|c|c|c|c|c|c|c|c|c|}
\hline & Leuko & $\begin{array}{c}\text { RAV- } \\
\text { DR }\end{array}$ & $\begin{array}{c}\text { RAV- } \\
\text { TL }\end{array}$ & DSST & C-FAS & C-AN & $\begin{array}{l}\text { Str- } \\
\text { CW }\end{array}$ & $\begin{array}{l}\text { Str- } \\
\text { Int }\end{array}$ \\
\hline \multicolumn{9}{|l|}{ Whites } \\
\hline$\overline{\text { Leuko }}$ & $0.529^{* * *}$ & -0.253 & -0.295 & -0.294 & -0.072 & -0.174 & -0.232 & -0.110 \\
\hline RAV-DR & -0.083 & $0.526^{\text {*** }}$ & 0.816 & 0.442 & 0.274 & 0.373 & 0.376 & 0.052 \\
\hline RAV-TL & -0.063 & 0.755 & $0.516^{* * *}$ & 0.523 & 0.346 & 0.429 & 0.441 & 0.147 \\
\hline DSST & -0.064 & 0.213 & 0.269 & $0.843^{\text {*** }}$ & 0.376 & 0.334 & 0.600 & 0.268 \\
\hline C-FAS & -0.023 & 0.163 & 0.234 & 0.265 & $0.366^{* * *}$ & 0.440 & 0.345 & 0.160 \\
\hline C-AN & -0.039 & 0.261 & 0.311 & 0.175 & 0.367 & $0.349^{* \star *}$ & 0.309 & 0.134 \\
\hline Str-CW & 0.003 & 0.186 & 0.226 & 0.424 & 0.262 & 0.160 & $0.429^{\star \star \star}$ & -0.134 \\
\hline Str-Int & -0.071 & -0.010 & 0.089 & 0.228 & 0.128 & 0.107 & -0.233 & $0.275^{* * *}$ \\
\hline \multicolumn{9}{|c|}{ African Americans } \\
\hline Leuko & $0.432^{* * *}$ & -2.10 & -0.281 & -0.270 & -0.213 & -0.172 & -0.197 & -0.108 \\
\hline RAV-DR & -0.007 & $0.390^{* \star *}$ & 0.790 & 0.416 & 0.307 & 0.285 & 0.275 & 0.153 \\
\hline RAV-TL & -0.079 & 0.729 & $0.440^{* * *}$ & 0.492 & 0.401 & 0.358 & 0.308 & 0.257 \\
\hline DSST & -0.075 & 0.188 & 0.220 & $0.556^{\star * *}$ & 0.557 & 0.489 & 0.534 & 0.311 \\
\hline C-FAS & -0.081 & 0.136 & 0.020 & 0.298 & $0.536^{* \star *}$ & 0.540 & 0.347 & 0.311 \\
\hline C-AN & -0.031 & 0.143 & 0.188 & 0.245 & 0.395 & $0.329^{* * *}$ & 0.357 & 0.204 \\
\hline Str-CW & -0.056 & 0.145 & 0.132 & 0.332 & 0.170 & 0.161 & $0.440^{* \star *}$ & -0.189 \\
\hline Str-Int & -0.021 & 0.046 & 0.139 & 0.194 & 0.219 & 0.129 & -0.339 & $0.154^{*}$ \\
\hline
\end{tabular}

Leuko $=$ Ln(leukoaraios+1), RAV-DR = RAVLT delayed recall, RAV-TL = RAVLT total learning, C-FAS $=$ COWA FAS, C-AN $=$ COWA animals, Str-CW $=$ Stroop color word, Str-Int $=$ Stroop interference Above diagonal: phenotypic correlations, $\rho_{\mathrm{p}}$, for traits modeled without covariates Below diagonal: phenotypic correlations, $\rho_{\mathrm{p}}$, for traits modeled with covariates Diagonal: heritabilities from polygenic analysis, $\mathrm{h}^{2}$, for traits modeled with covariates For all traits modeled with covariates, biometric models included age, sex, and education. The biometric model for $\ln ($ leukoaraiosis +1 ) also included TIV.

Null hypothesis of tests: $\mathrm{h}^{2}=0$ (diagonal)

${ }^{*} 0.01<$ p-value $<0.05,{ }^{* *} 0.001<$ p-value $<0.01,{ }^{* * *}$ p-value $<0.001$

Table 5. Biometrically derived phenotypic correlations among traits

environmental effects. For all estimates of genetic and environmental correlations, adjustment covariates were included in the biometric models.

The majority of significant genetic correlations observed were in whites. In whites, significant genetic correlations ranged from 0.263 (RAVLT total learning and DSST) to 0.918 (RAVLT total learning and RAVLT delayed recall). Other highly significant genetic correlations ( $p$-value $<0.001)$ were between DSST and Stroop color word $(0.7)$ and between RAVLT total learning and COWA animals (0.55). Many of the pairs involving RAVLT, COWA, and DSST also showed significant genetic correlations, ranging from 0.263 to 0.476 . Leukoaraiosis and RAVLT had a marginally significant negative genetic correlation $(-0.28)$, indicating that genes shared between these two traits have opposite effects on the traits (for example, a certain genetic variation may increase leukoaraiosis volume while decreasing learning scores). No other evidence of pleiotropic effects was found between leukoaraiosis and cognitive measures.

In contrast to the relative abundance of genetic correlations between these measures, there were very few significant environmental correlations in whites. The most significant 
environmental correlation was between the trait pair that also had the highest genetic correlation, RAVLT total learning and RAVLT delayed recall (0.586), although the environmental correlation was substantially less than the genetic correlation. This indicates that for this trait pair, shared genetic effects have a stronger influence than shared environmental effects, though both contribute to the observed strong phenotypic correlation. The only other highly significant environmental correlation was between Stroop color word and Stroop interference (-0.427). This correlation is negative since poor cognitive performance is indicated by a low score on Stroop color word but by a high score on Stroop interference. Only two other trait pairs exhibited even marginally significant environmental correlations in whites. Leukoaraiosis had a negative environmental correlation with Stroop interference $(-0.274)$ and the two measures from the COWA had a positive environmental correlation (0.293).

\begin{tabular}{|c|c|c|c|c|c|c|c|c|}
\hline & Leuko & $\begin{array}{c}\text { RAV- } \\
\text { DR }\end{array}$ & $\begin{array}{c}\text { RAV- } \\
\text { TL } \\
\end{array}$ & DSST & C-FAS & C-AN & $\begin{array}{l}\text { Str- } \\
\text { CW }\end{array}$ & $\begin{array}{l}\text { Str- } \\
\text { Int }\end{array}$ \\
\hline \multicolumn{9}{|l|}{ Whites } \\
\hline Leuko & $0.529^{* \star *}$ & 0.078 & 0.178 & -0.008 & -0.092 & -0.136 & -0.066 & $-0.274^{*}$ \\
\hline RAV-DR & -0.233 & $0.526^{* * *}$ & $0.586^{* * *}$ & -0.015 & -0.072 & 0.185 & 0.087 & -0.024 \\
\hline RAV-TL & $-0.280^{*}$ & $0.918^{* * *}$ & $0.516^{* * *}$ & 0.354 & 0.149 & 0.142 & 0.128 & 0.092 \\
\hline DSST & -0.092 & $0.329^{* *}$ & $0.263^{*}$ & $0.843^{* * *}$ & 0.107 & 0.015 & 0.021 & 0.276 \\
\hline C-FAS & 0.062 & $0.476^{* *}$ & $0.350^{*}$ & $0.418^{* *}$ & $0.366^{* * *}$ & $0.293^{*}$ & 0.163 & 0.185 \\
\hline C-AN & 0.084 & $0.372^{*}$ & $0.550^{* *}$ & $0.310^{*}$ & $0.495^{*}$ & $0.349^{\star \star *}$ & 0.023 & 0.157 \\
\hline Str-CW & 0.078 & 0.296 & $0.336^{*}$ & $0.700^{* * *}$ & $0.413^{*}$ & $0.371^{*}$ & $0.429^{* \star *}$ & $-0.427^{* * *}$ \\
\hline Str-Int & 0.230 & 0.010 & 0.091 & 0.280 & 0.007 & -0.004 & 0.146 & $0.275^{\star \star \star}$ \\
\hline \multicolumn{9}{|c|}{ African Americans } \\
\hline Leuko & $0.432^{* * *}$ & -0.161 & -0.261 & -0.232 & -0.169 & -0.127 & -0.194 & 0.130 \\
\hline RAV-DR & 0.215 & $0.390^{\star * *}$ & $0.596^{\star \star *}$ & $0.327^{*}$ & 0.167 & 0.166 & 0.040 & 0.035 \\
\hline RAV-TL & 0.158 & $0.915^{* * *}$ & $0.440^{* * *}$ & $0.401^{* *}$ & $0.322^{*}$ & 0.128 & 0.017 & 0.035 \\
\hline DSST & 0.078 & 0.036 & 0.045 & $0.556^{* * *}$ & $0.442^{* *}$ & $0.270^{*}$ & -0.005 & 0.237 \\
\hline C-FAS & 0.010 & 0.102 & 0.075 & 0.179 & $0.536^{* * *}$ & $0.313^{*}$ & -0.019 & 0.113 \\
\hline C-AN & 0.124 & 0.101 & 0.286 & 0.228 & $0.533^{* *}$ & $0.329^{* * *}$ & 0.158 & 0.020 \\
\hline Str-CW & 0.128 & 0.293 & 0.278 & $0.698^{* * *}$ & $0.363^{*}$ & 0.167 & $0.440^{* \star *}$ & $-0.541^{* * *}$ \\
\hline Str-Int & -0.422 & 0.010 & 0.432 & 0.164 & 0.507 & 0.522 & 0.099 & $0.154^{*}$ \\
\hline
\end{tabular}

Leuko $=$ Ln(leukoaraios +1$),$ RAV-DR $=$ RAVLT delayed recall, RAV-TL = RAVLT total learning, C-FAS $=$ COWA FAS, C-AN = COWA animals, Str-CW $=$ Stroop color word, Str-Int $=$ Stroop interference Above diagonal: environmental correlations, $\rho_{\mathrm{e}}$

Below diagonal: genetic correlations, $\rho_{\mathrm{g}}$

Diagonal: heritabilities from univariate polygenic analysis, $\mathrm{h}^{2}$, for adjusted traits

For all adjusted traits, biometric models included age, sex, and education. The biometric model for $\ln$ (leukoaraiosis+1) also included TIV.

Null hypothesis of tests: $\rho_{\mathrm{e}}=0$ (above diagonal)

Null hypothesis of tests: $\rho_{g}=0$ (below diagonal)

Null hypothesis of tests: $\mathrm{h}^{2}=0$ (diagonal)

${ }^{*} 0.01<$ p-value $<0.05,{ }^{* *} 0.001<$ p-value $<0.01,{ }^{* * *}$ p-value $<0.001$

Table 6. Genetic and enviromental correlations among traits 
The overall patterns of genetic and environmental correlations in African Americans were strikingly similar to the patterns observed in whites. However, many of the genetic correlations in African Americans did not reach statistical significance due to larger standard errors in their estimates, and there was slightly more evidence of shared environmental effects. Two of the four highly significant genetic correlations observed in whites were also observed in African Americans. RAVLT total learning and RAVLT delayed recall were the most strongly genetically correlated (0.915) followed by DSST and Stroop color word (0.698). The only other significant genetic correlations were between the two measures of COWA (0.533) and between COWA FAS and Stroop color word (0.363). There were no significant genetic correlations between leukoaraiosis and any of the cognitive traits.

As with whites, the most highly significant environmental correlation was between the two measures of RAVLT (0.596) and between Stroop color word and Stroop interference (-0.541). The direction and magnitudes of the correlations for these traits were also the same in African Americans as they were in whites. The other strongly significant environmental correlations observed in African Americans were between DSST and RAVLT total learning (0.401) and DSST and COWA FAS (0.442). Four additional pairs of traits also exhibited marginally significant environmental correlations, including the two COWA measures (0.313) that also showed a marginally significant environmental correlation in whites.

\section{Discussion}

\subsection{Heritability of leukoaraiosis}

In our study, the heritability of leukoaraiosis was 0.529 in whites and 0.432 in African Americans, after adjustment for age, sex, and total intracranial volume. This finding is consistent with heritability estimates from comparable studies. Heritability was estimated to be 0.71 in study of white male twins (mean age 73 years) after adjustment for age and head size (Carmelli et al., 1998) and 0.55 in a sample of stroke- and dementia-free subjects (mean age 61.0 years) after adjustment for sex, age, age ${ }^{2}$, and total cranial volume (Atwood et el., 2004). Turner et al. (2004) showed that leukoaraiosis has a consistently high heritability even after adjustment for blood pressure. These high heritabilities imply that much of the inter-individual differences in variation of leukoaraiosis are due to differences in genetics.

\subsection{Heritability of cognitive function}

Our study estimates that the majority of heritabilities of seven measures of cognitive function in whites and African Americans are between $\sim 0.35$ and $\sim 0.55$. Previous studies of the heritability of cognitive functioning has been conducted primarily in twin studies that use factor analysis to identify a common factor to act as a proxy for overall cognitive function, and the findings point to a higher heritability for this measure than was estimated in our study. For example, McGue and Christensen (2002) estimated the heritability of general cognitive function as measured by five cognitive tasks comprised of fluency, digit span, and recall to be 0.70. Finkel et al. (1995) peformed quantitative genetic analysis on four measures of cognitive function (verbal, spatial, perceptual speed, and memory) and showed that heritability for a general cognitive factor was between 0.54 and 0.81 in two samples across several age groups of adults (from young to elderly).

Our results show that there are differences in heritability across cognitive measures, with processing speed having the highest heritability in whites (0.843) and African Americans 
(0.556). Other studies have also shown that processing speed has the strongest genetic influence among measures of executive function (Carmelli et al., 2002). The heritability of executive function generally tends to be higher than that of memory, with heritabilities for executive functions between 0.34-0.70 (Carmelli et al., 2002; Sleegers et al., 2007) and heritabilities for memory function closer to 0.2-0.4 (McGue \& Christensen, 2001; Plomin et al., 1994; Sleegers et al., 2007). In GENOA whites, memory measures (RAVLT) had slightly higher heritabilities than most of the executive function tests except for DSST. However, in African Americans, heritability of memory measures tended to be similar to those of executive funtion.

While existing research supports true differences in the heritabilities of cognitive domains, a portion of the observed differences may be due to the nature of the tests and scoring procedures. More complex tests such as Stroop may be more susceptible to measurement error than less complex tests such as DSST, and test scores that are mathematically manipulated (e.g., Stroop interference) are particularly susceptible to this type of error. Increased measurement error may lead to lower heritability estimations as well as weaker genetic and environmental correlations among trait pairs.

\subsection{Bivariate variance component analysis in leukoaraiosis and cognitive traits}

We found that in GENOA whites, measures of cognitive function exhibit substantial evidence of genetic correlation (pleiotropy), with measures of similar tests showing stronger genetic correlation. Evidence of phenotypic correlation due to shared environment was largely limited to a smaller number of cognitive trait pairs in African Americans. However, we detected no evidence of genetic or environmental correlations between measures of cognitive function and leukoaraiosis.

The lack of evidence of genetic correlation between leukoaraiosis and cognitive function in this study stands in contrast to a study conducted by Carmelli, et al. (2002), which used maximum likelihood nested modeling techniques to estimate the proportion of variance in leukoaraiosis and executive control function due to genetic, shared environmental, and non-shared environmental effects in 142 pairs of elderly twins (mean age $=73$ years). The total phenotypic correlation between leukoaraiosis and executive function was -0.20 , and they found that $70 \%$ of the total phenotypic correlation was accounted for by shared genes while $30 \%$ was accounted for by shared environments. While this is substantial, the contribution of overlapping genes (genes shared between the executive control factor and leukoaraiosis) to the genetic variance in executive function was only $8 \%$ due to the relatively low phenotypic correlation. The lack of detecting shared genetic or enviornmental effects between leukoaraiosis and measures of cognitive function in the GENOA study was partially due to the very low phenotypic correlations among leukoaraiosis and the measures of cognitive function, which may be a function of the younger average age of GENOA participants.

Other studies of the shared genetic components of cognitive traits tend to focus on change in cognition over time. Variance components analysis of the relationship between cognitive change and perception speed in a study of 292 twins aged $40-84$ revealed that $90 \%$ of the age-related variance and $70 \%$ of the genetic variance in cognitive function was shared with perception speed, demonstrating that there is a genetic component to processing speed which also influences general cognitive functioning (Finkel \& Pedersen, 2000). This finding was supported by the GENOA study, as processing speed (DSST) exhibited genetic correlation with nearly all of the other cognitive measures in whites. Although GENOA 
African Americans showed little evidence for genetic correlation among cognitive traits, a significant genetic correlation was found for DSST and Stroop color word.

\subsection{Differences in the genetic parameters for whites and African Americans}

Heritabilities of leukoaraiosis and cognitive measures showed a consistent pattern in whites and African Americans. DSST had the highest heritability (0.883 in whites, 0.556 in African Americans), Stroop interference had the lowest heritability ( 0.275 in whites, 0.154 in African Americans), and leukoaraiosis and the other cognitive measures had mid-range heritabilities (0.35-0.53 in whites, 0.33-0.54 in African Americans). However, heritabilities showed a clear trend of being lower in African Americans, with COWA FAS being the only notable exception (heritability $=0.366$ in whites, 0.536 in African Americans). A similar trend was observed for overall phenotypic correlations and genetic correlations, with African Americans showing a similar but weaker correlational structure.

There are several reasons that could account for the lower observed heritabilities in African Americans. Since heritability is the fraction of the total variability of the trait accounted for by additive genetic factors, lower heritabilities could result from greater trait variation (a larger denominator) or from a smaller contribution from additive genetic effects (a smaller numerator). Differences in either the numerator or the demoninator could be due to true population differences between whites and African Americans, or they could simply be artefacts of the GENOA samples, such as differences in age or family structure. We examined the possibility that age or family structure may be responsible for the differences in heritability by re-estimating heritabilities in sub-samples of each ethnic group that were of equivalent age or had equivalent family compositions (data not shown). Trends in the heritabilities remained consistent across sub-samples, so we concluded that the lower heritabilities observed in the African American GENOA sample reflect a true difference in the population parameters of the groups studied and is not an artefact of the GENOA sample structure. However, it is possible that the same factors hypothesized to contribute to variability in test scores among ethnic groups (e.g., cultural variability in familiarity with testing response sets, motivation and attitudes toward test-taking) may have increased the measurement error of the cognitive function tests in the African American sample, resulting in lower heritability estimates for this group.

Lower heritabilities of leukoaraiosis and the seven cognitive traits as well as differences in the genetic and environmental correlations between GENOA whites and African Americans suggest that non-genetic factors have a greater effect in African Americans than in whites for all of the brain traits studied. Though similar patterns were observed in whites and African Americans, genetic correlations (evidence of shared genetic effects) among cognitive traits tended to be higher and more significant in whites. While very little evidence of environmental correlation (shared environmental effects) between cognitive traits was observed in whites, eight of the 21 pairs of cognitive traits (38\%) had evidence of significant environmental correlation in African Americans. Therefore, it is likely that non-genetic factors are indeed playing a larger role in affecting variation in brain traits in African American GENOA sample.

\subsection{The effect of age on genetic parameter estimation}

Most studies of the genetic and environmental factors associated with leukoaraiosis have had samples composed of individuals who have already experienced clinical endpoints such 
as stroke or severe cognitive decline. The relatively young age range of our sample provided the unique opportunity to examine the relationships between leukoaraiosis and cognitive phenotypes in asymptomatic individuals, at a time when preventive treatment would be most effective. However, the young age of our sample also imposed constraints, including the limited variability in the leukoaraiosis phenotype. In addition, it has been shown that heritabilities of cognitive traits tend to vary with age (Knopman et al., 2001; Mattay, 2008). Since this study was cross-sectional, we did not have the ability to examine how heritabilities and genetic correlations change over time. Differential heritabilities across age groups also implies that there may be genetic factors that show age-related changes in penetrance with respect to cognitive traits. It is therefore plausible that the genetic correlations between leukoaraiosis and cognitive traits may also change with age.

\section{Conclusion}

The complex relationship between subclinical measures and clinical outcomes underscores the importance of studying leukoaraiosis and cognitive decline as the predecessors of stroke and dementia in order to better elucide the shared and unique contributions of genetic factors to the disease pathologies that result from hypertension and other risk factors. This study illustrates that the genetic and environmental influences on the subclinical measures of stroke and dementia vary substantially between measures of structural injury (leukoaraiosis) and performance on cognitive tests, and that unique patterns of genetic and environmental correlation exist across cognitive domains (memory vs. executive function). All of the traits studied demonstrate significant heritability, indicating that genetic factors account for a substantial portion of the variability in leukoaraiosis as well as multiple measures of cognitive function. Some of the cognitive measures, particularly those that assessed similar cognitive domains, demonstrated a significant degree of shared genetic effects, while others demonstrated a greater degree of shared environmental effects. Leukoaraiosis, while heritable, does not share any genetic or environmental influences with the cognitive measures. Patterning of heritability and genetic/environmental correlations showed definitive trends that were consistent across ethic groups, but one clear difference was that cognitive measures tended to have more shared genetic effects in whites and more shared enviornmental effects in African Americans. These results indicate that the environmental and genetic factors that predispose individuals to leukoaraiosis and cognitive decline are likely to be best understood and studied at the family and community levels. Integrating genetic information with family history and cultural or socio-economic stressors and supports is likely to contribute to new knowledge of the unique and shared risk factors for these traits, and thus lead to more effective preventive strategies.

\section{Acknowledgements}

Data collection and statistical analysis was supported by the National Institutes of Health research grants U10 HL54457, U01 HL054481, and R01 NS041558. We would like to thank Eric Boerwinkle and Myriam Fornage (University of Texas Health Science Center), Clifford Jack, Jr. (Mayo Clinic), Wei Zhao and Patricia Peyser (University of Michigan), Reagan Kelly (Z-Tech at National Center for Toxological Research), the research staff at the Mayo Clinic and University of Mississippi field centers, and the families that participated in the GENOA study. 


\section{References}

Almasy, L., \& Blangero, J. (1998). Multipoint Quantitative-Trait Linkage Analysis in General Pedigrees. American Journal of Human Genetics, Vol. 62, No. 5, pp. 1198-1211.

Alzheimer's Association. (2008). Alzheimer's Disease Facts and Figures 2008: 10 Million U.S. Baby Boomers Will Develop Alzheimer's Disease, Vol. 4, No. 2, pp. 110-133.

American Psychiatric Association. (2000). Diagnostic and Statistical Manual of Mental Disorders-IV-TR. Washington, D.C.

Atwood, L.D., Wolf, P.A., Heard-Costa, N.L., Massaro, J.M., Beiser, A., D'Agostino, R.B., \& DeCarli, C. (2004). Genetic Variation in White Matter Hyperintensity Volume in the Framingham Study. Stroke, Vol. 35, No. 7, pp. 1609-1613.

Boustani, M., Peterson, B., Hanson, L., Harris, R., Lohr, K.N., \& U.S. Preventive Services Task Force. (2003). Screening for Dementia in Primary Care: A Summary of the Evidence for the U.S. Preventive Services Task Force. Annals of Internal Medicine, Vol. 138, No. 11, pp. 927-937.

Carmelli, D., DeCarli, C., Swan, G.E., Jack, L.M., Reed, T., Wolf, P.A., \& Miller, B.L. (1998). Evidence for Genetic Variance in White Matter Hyperintensity Volume in Normal Elderly Male Twins. Stroke, Vol. 29, No. 6, pp. 1177-1181.

Carmelli, D., Reed, T., \& DeCarli, C. (2002). A Bivariate Genetic Analysis of Cerebral White Matter Hyperintensities and Cognitive Performance in Elderly Male Twins. Neurobiology of Aging, Vol. 23, No. 3, pp. 413-420.

Charlesworth, J., Kramer, P.L., Dyer, T., Diego, V., Samples, J.R., Craig, J.E., Mackey, D.A., Hewitt, A.W., Blangero, J., \& Wirtz, M.K. (2010). The Path to Open-Angle Glaucoma Gene Discovery: Endophenotypic Status of Intraocular Pressure, Cup-toDisc Ratio, and Central Corneal Thickness. Investigative Ophthalmology and Visual Science, Vol. 51, No. 7, pp. 3509-3514.

Cheverud, J.M., Ehrich, T.H., Vaughn, T.T., Koreishi, S.F., Linsey, R.B., \& Pletscher, L.S. (2004). Pleiotropic Effects on Mandibular Morphology II: Differential Epistasis and Genetic Variation in Morphological Integration. Journal of Experimental Zoology Part B: Molecular and Developmental Evolution, Vol. 302, No. 5, pp. 424-435.

Comuzzie, A.G., Blangero, J., Mahaney, M.C., Mitchell, B.D., Stern, M.P., \& MacCluer, J.W. (1994). Genetic and Environmental Correlations among Skinfold Measures. International Journal of Obesity and Related Metabolic Disorders, Vol. 18, No. 6, pp. 413418.

Daniels, P.R., Kardia, S.L., Hanis, C.L., Brown, C.A., Hutchinson, R., Boerwinkle, E., Turner, S.T., \& Genetic Epidemiology Network of Arteriopathy study. (2004). Familial Aggregation of Hypertension Treatment and Control in the Genetic Epidemiology Network of Arteriopathy (GENOA) Study. American Journal of Medicine, Vol. 116, No. 10, pp. 676-681.

Deary, I.J., Wright, A.F., Harris, S.E., Whalley, L.J., \& Starr, J.M. (2004). Searching for Genetic Influences on Normal Cognitive Ageing. Trends in Cognitive Sciences, Vol. 8, No. 4, pp. 178-184.

DeKosky, S.T., \& Marek, K. (2003). Looking Backward to Move Forward: Early Detection of Neurodegenerative Disorders. Science, Vol. 302, No. 5646, pp. 830-834.

Dickstein, D.L., Walsh, J., Brautigam, H., Stockton, S.D.JJ, Gandy, S., \& Hof, P.R. (2010). Role of Vascular Risk Factors and Vascular Dysfunction in Alzheimer's Disease. Mount Sinai Journal of Medicine, Vol. 77, No. 1, pp. 82-102. 
Donnan, G.A., Fisher, M., Macleod, M., \& Davis, S.M. (2008). Stroke. Lancet, Vol. 371, No. 9624, pp. 1612-1623.

Essink-Bot, M.L., Pereira, J., Packer, C., Schwarzinger, M., \& Burstrom, K. (2002). CrossNational Comparability of Burden of Disease Estimates: The European Disability Weights Project. Bulletin of the World Health Organization, Vol. 80, No. 8, pp. 644-652.

Family Blood Pressure Program Investigators. (2002). Multi-Center Genetic Study of Hypertension: The Family Blood Pressure Program (FBPP). Hypertension, Vol. 39, No. 1, pp. 3-9.

Finkel, D., Pedersen, N.L., McGue, M., \& McClearn, G.E. (1995). Heritability of Cognitive Abilities in Adult Twins: Comparison of Minnesota and Swedish Data. Behavior Genetics, Vol. 25, No. 5, pp. 421-431.

Finkel, D., \& Pedersen, N.L. (2000). Contribution of Age, Genes, and Environment to the Relationship between Perceptual Speed and Cognitive Ability. Psychology and Aging, Vol 15, No. 1, pp. 56-64.

Fornage, M.F., Debette, S., Bis, J.C., Schmidt, H., Ikram, M.A., Dufouil, C., Sigurdsson, S., Lumley, T., DeStefano, A.L., Fazekas, F., et. al. (2011). Genome-Wide Association Studies of Cerebral White Matter Lesion Burden. Annals of Neurology, Vol. 69, No. 6, pp. 928-939.

Geldmacher, D.S., \& Whitehouse, P.J.Jr. (1997). Differential Diagnosis of Alzheimer's Disease. Neurology, Vol. 48, No. 5, Supplement 6, pp. S2-S9.

Golden, C.J. (1978). Stroop Color and Word Test: A Manual for Clinical and Experimental Uses, Shoelting Company, Wood Dale, IL.

Haan, M.N., and Wallace, R. (2004). Can Dementia be Prevented? Brain Aging in a Population-Based Context. Annual Review of Public Health, Vol. 25, pp. 1-24.

Hassan, A., Hunt, B.J., O'Sullivan, M., Parmar, K., Bamford, J.M., Briley, D., Brown, M.M., Thomas, D.J., \& Markus, H.S. (2003). Markers of Endothelial Dysfunction in Lacunar Infarction and Ischaemic Leukoaraiosis. Brain, Vol. 126, No. 2, pp. 424-432.

Hassan, A., Hunt, B.J., O'Sullivan, M., Bell, R., D'Souza, R., Jeffery, S., Bamford, J.M., \& Markus, H.S. (2004). Homocysteine is a Risk Factor for Cerebral Small Vessel Disease, Acting Via Endothelial Dysfunction. Brain, Vol. 127, No. 1, pp. 212-219.

Hodgkin, J. (1998). Seven Types of Pleiotropy. International Journal of Developmental Biology, Vol. 42, No. 3, pp. 501-505.

Ivnik, R., Malec, J., and Smith, G. (1992). Mayo's Older Americans Normative Studies: Updated AVLT Norms for Ages 56 to 97. The Clinical Neuropsychologist, Vol. 6, Supplement, pp. 83-104.

Jack, C.R.,Jr, Twomey, C.K., Zinsmeister, A.R., Sharbrough, F.W., Petersen, R.C., \& Cascino, G.D. (1989). Anterior Temporal Lobes and Hippocampal Formations: Normative Volumetric Measurements from MR Images in Young Adults. Radiology, Vol. 172, No. 2, pp. 549-554.

Jack, C.R.,Jr, O'Brien, P.C., Rettman, D.W., Shiung, M.M., Xu, Y., Muthupillai, R., Manduca, A., Avula, R., \& Erickson, B.J. (2001). FLAIR Histogram Segmentation for Measurement of Leukoaraiosis Volume. Journal of Magnetic Resonance Imaging, Vol. 14, No. 6, pp. 668-676.

Knopman, D., Boland, L.L., Mosley, T., Howard, G., Liao, D., Szklo, M., McGovern, P., Folsom, A.R., \& Atherosclerosis Risk in Communities (ARIC) Study Investigators. 
(2001). Cardiovascular Risk Factors and Cognitive Decline in Middle-Aged Adults. Neurology, Vol. 56, No. 1, pp. 42-48.

Launer, L.J., Ross, G.W., Petrovitch, H., Masaki, K., Foley, D., White, L.R., \& Havlik, R.J. (2000). Midlife Blood Pressure and Dementia: The Honolulu-Asia Aging Study. Neurobiology of Aging, Vol. 21, No. 1, pp. 49-55.

Lezak, M. (1995). Neuropsychological Assessment. Oxford University Press, New York, NY.

Lopez, A.D., Mathers, C.D., Ezzati, M., Jamison, D.T., \& Murray, C.J. (2001). Global and Regional Burden of Disease and Risk Factors, 2001: Systematic Analysis of Population Health Data. The Lancet, Vol. 367, No. 9524, pp. 1747-1757.

Markus, H.S., Hunt, B., Palmer, K., Enzinger, C., Schmidt, H., \& Schmidt, R. (2005). Markers of Endothelial and Hemostatic Activation and Progression of Cerebral White Matter Hyperintensities: Longitudinal Results of the Austrian Stroke Prevention Study. Stroke, Vol. 36, No. 7, pp. 1410-1414.

Markus, H.S. (2008). Genes, Endothelial Function and Cerebral Small Vessel Disease in Man. Experimental Physiology, Vol. 93, No. 1, pp. 121-127.

Mattay, V.S., Goldberg, T.E., Sambataro, F., \& Weinberger, D.R. (2008). Neurobiology of Cognitive Aging: Insights from Imaging Genetics. Biological Psychology, Vol. 79, No. 1, pp. 9-22.

McGue, M., \& Christensen, K. (2001). The Heritability of Cognitive Functioning in very Old Adults: Evidence from Danish Twins Aged 75 Years and Older. Psychology and Aging, Vol. 16, No. 2, pp. 272-280.

McGue, M., \& Christensen, K. (2002). The Heritability of Level and Rate-of-Change in Cognitive Functioning in Danish Twins Aged 70 Years and Older. Experimental Aging Research, Vol. 28, No. 4, pp. 435-451.

O'Sullivan, M. (2008). Leukoaraiosis. Practical Neurology, Vol. 8, No. 1, pp. 26-38.

Pantoni, L., Poggesi, A., \& Inzitari, D. (2007). The Relation between White-Matter Lesions and Cognition. Current Opinion in Neurology, Vol. 20, No. 4, 390-397.

Paternoster, L., Chen, W., \& Sudlow, C.L. (2009). Genetic Determinants of White Matter Hyperintensities on Brain Scans: A Systematic Assessment of 19 Candidate Gene Polymorphisms in 46 Studies in 19,000 Subjects. Stroke, Vol. 40, No. 6, pp. 20202026.

Plomin, R., Pedersen, N.L., Lichtenstein, P., \& McClearn, G.E. (1994). Variability and Stability in Cognitive Abilities are Largely Genetic Later in Life. Behavior Genetics, Vol. 24, No. 3, pp. 207-215.

Pohjasvaara, T., Mantyla, R., Ylikoski, R., Kaste, M., \& Erkinjuntti, T. (2000). Comparison of Different Clinical Criteria (DSM-III, ADDTC, ICD-10, NINDS-AIREN, DSM-IV) for the Diagnosis of Vascular Dementia. National Institute of Neurological Disorders and Stroke-Association Internationale Pour La Recherche Et l'Enseignement En Neurosciences. Stroke, Vol. 31, No. 12, pp. 2952-2957.

Prins, N.D., van Dijk, E.J., den Heijer, T., Vermeer, S.E., Koudstaal, P.J., Oudkerk, M., Hofman, A., \& Breteler, M.M. (2004). Cerebral White Matter Lesions and the Risk of Dementia. Archives of Neurology, Vol. 61, No. 10, pp. 1531-1534.

R Core Development Team. (2008). R: A Language and Environment for Statistical Computing.

Rey, A. (1964). L'Examen Clinique en Psychologie. Presses Universitaires de France. 
Roger, V.L., Go, A.S., Lloyd-Jones, D.M., Adams, R.J., Berry, J.D., Brown, T.M., Carnethon, M.R., Dai, S., de Simone, G., Ford, E.S., et al. (2011). Heart Disease and Stroke Statistics 2011 Update: A Report From the American Heart Association. Circulation, Vol. 123, pp. e18-e209.

Schmidt, R., Scheltens, P., Erkinjuntti, T., Pantoni, L., Markus, H.S., Wallin, A., Barkhof, F., \& Fazekas, F. (2004). White Matter Lesion Progression: A Surrogate Endpoint for Trials in Cerebral Small-Vessel Disease. Neurology, Vol. 63, No. 1, pp. 139-144.

Schmidt, R., Petrovic, K., Ropele, S., Enzinger, C., \& Fazekas, F. (2007). Progression of Leukoaraiosis and Cognition. Stroke, Vol. 38, No. 9, pp. 2619-2625.

Sierra, C., \& Coca, A. (2006). White Matter Lesions and Cognitive Impairment as Silent Cerebral Disease in Hypertension. Scientific World Journal, Vol. 6, pp. 494-501.

Sing, C.F., Boerwinkle, E., Moll, P.P., \& Templeton, A.R. (1987). Characterization of Genes affecting Quantitative Traits in Humans. In Proceedings of the Second International Conference on Quantitative Genetics, B. Weir, E.J. Eisen, M.M. Goodman, and G. Namkoong, eds., pp. 250-269, Sinauer Associates, Inc., Raliegh, NC,

Sleegers, K., de Koning, I., Aulchenko, Y.S., van Rijn, M.J., Houben, M.P., Croes, E.A., van Swieten, J.C., Oostra, B.A., \& van Duijn, C.M. (2007). Cerebrovascular Risk Factors do Not Contribute to Genetic Variance of Cognitive Function: The ERF Study. Neurobiology of Aging, Vol. 28, No. 5, pp. 735-741.

Stroop, J. (1935). Studies of Inference in Serial Verbal Reactions. Journal of Experimental Psychology, Vol. 18, pp. 643-662.

Szolnoki, Z., \& Melegh, B. (2006). Gene-Gene and Gene-Environment Interplay Represent Specific Susceptibility for Different Types of Ischaemic Stroke and Leukoaraiosis. Current Medicinal Chemistry, Vol. 13, No. 14, pp. 1627-1634.

Turner, S.T., \& Boerwinkle, E. (2000). Genetics of Hypertension, Target-Organ Complications, and Response to Therapy. Circulation, Vol. 102, No. 20, Supplement 4, pp. 40-45.

Turner, S.T., Jack, C.R., Fornage, M., Mosley, T.H., Boerwinkle, E., \& de Andrade, M. (2004). Heritability of Leukoaraiosis in Hypertensive Sibships. Hypertension, Vol. 43, No. 2, pp. 483-487.

Valenzuela, M.J., \& Sachdev, P. (2006). Brain Reserve and Cognitive Decline: A NonParametric Systematic Review. Psychological Medicine, Vol. 36, No. 8, pp. 1065-1073.

van Dijk, E.J., Breteler, M.M., Schmidt, R., Berger, K., Nilsson, L.G., Oudkerk, M., Pajak, A., Sans, S., de Ridder, M., Dufouil, C. et al. (2004). The Association between Blood Pressure, Hypertension, and Cerebral White Matter Lesions: Cardiovascular Determinants of Dementia Study. Hypertension, Vol. 44, No. 5, pp. 625-630.

Wechsler, D. (1981). The Wechsler Adult Intelligence Scale-Revised. Psychological Corporation, New York.

Zou, L., Sriswasdi, S., Ross, B., Missiuro, P.V., Liu, J., \& Ge, H. (2008). Systematic Analysis of Pleiotropy in C. Elegans Early Embryogenesis. PLoS Computational Biology, Vol. 4, No. 2, e1000003. 


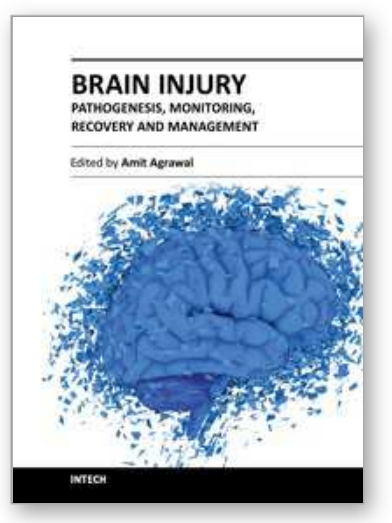

\author{
Brain Injury - Pathogenesis, Monitoring, Recovery and \\ Management \\ Edited by Prof. Amit Agrawal
}

ISBN 978-953-51-0265-6

Hard cover, 522 pages

Publisher InTech

Published online 23, March, 2012

Published in print edition March, 2012

The present two volume book "Brain Injury" is distinctive in its presentation and includes a wealth of updated information on many aspects in the field of brain injury. The Book is devoted to the pathogenesis of brain injury, concepts in cerebral blood flow and metabolism, investigative approaches and monitoring of brain injured, different protective mechanisms and recovery and management approach to these individuals, functional and endocrine aspects of brain injuries, approaches to rehabilitation of brain injured and preventive aspects of traumatic brain injuries. The collective contribution from experts in brain injury research area would be successfully conveyed to the readers and readers will find this book to be a valuable guide to further develop their understanding about brain injury.

\title{
How to reference
}

In order to correctly reference this scholarly work, feel free to copy and paste the following:

Jennifer A. Smith, Thomas H. Mosley, Jr., Stephen T. Turner and Sharon L. R. Kardia (2012). Shared Genetic Effects among Measures of Cognitive Function and Leukoaraiosis, Brain Injury - Pathogenesis, Monitoring, Recovery and Management, Prof. Amit Agrawal (Ed.), ISBN: 978-953-51-0265-6, InTech, Available from: http://www.intechopen.com/books/brain-injury-pathogenesis-monitoring-recovery-and-management/sharedgenetic-effects-among-measures-of-cognitive-function-and-leukoaraiosis

\section{INTECH}

open science | open minds

\author{
InTech Europe \\ University Campus STeP Ri \\ Slavka Krautzeka 83/A \\ 51000 Rijeka, Croatia \\ Phone: +385 (51) 770447 \\ Fax: +385 (51) 686166 \\ www.intechopen.com
}

\author{
InTech China \\ Unit 405, Office Block, Hotel Equatorial Shanghai \\ No.65, Yan An Road (West), Shanghai, 200040, China \\ 中国上海市延安西路65号上海国际贵都大饭店办公楼 405 单元 \\ Phone: +86-21-62489820 \\ Fax: +86-21-62489821
}


(C) 2012 The Author(s). Licensee IntechOpen. This is an open access article distributed under the terms of the Creative Commons Attribution 3.0 License, which permits unrestricted use, distribution, and reproduction in any medium, provided the original work is properly cited. 